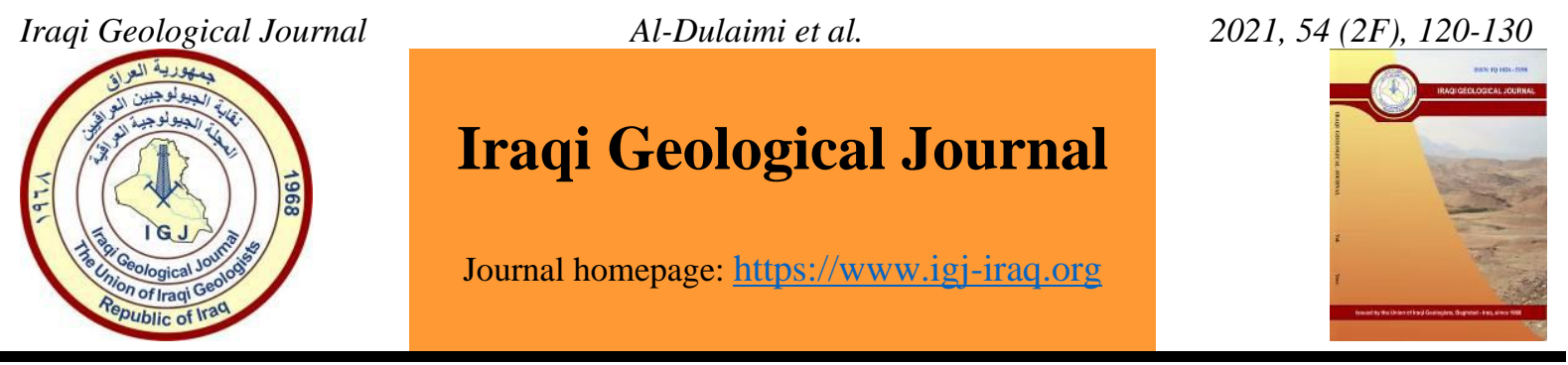

\title{
Concentration, Distribution, and Potential Sources of Heavy Metals in Households Dust in Al-Fallujah, Iraq
}

\author{
Eman M. Al-Dulaimi ${ }^{1}$, Sufyan M. Shartooh ${ }^{1}$ and Emad A. Al-Heety ${ }^{2, *}$ \\ Department of Biology, College of Science, University of Anbar, Anbar, Iraq \\ 2 Department of Applied Geology, College of Science, University of Anbar, Iraq \\ * Correspondence: emadsalah@uoanbar.edu.iq
}

Received: 17 June 2021; Accepted: 1 September 2021; Published: 31 December 2021

\begin{abstract}
Household dust pollution with heavy metals attracted the attention of researchers and environmental managers due to the risk of the health of these metals. The study aims are to determine heavy metals concentrations $(\mathrm{Cd}$, $\mathrm{Cr}, \mathrm{Cu}, \mathrm{Ni}, \mathrm{Pb}, \mathrm{Zn}$ ), their spatial distribution, and their potential sources in the household dust of Al-Fallujah City, Iraq. The dust was sampled from 50 houses. The heavy metals levels in the dust were measured using the atomic absorption spectrophotometry method. The mean concentration of heavy metal was ordered as following: $\mathrm{Zn}(292.85 \mathrm{mg} / \mathrm{kg})>\mathrm{Cr}(289.45 \mathrm{mg} / \mathrm{kg})>\mathrm{Ni}(105.72 \mathrm{mg} / \mathrm{kg})>\mathrm{Pb}(75.57 \mathrm{mg} / \mathrm{kg})>\mathrm{Cu}(65.03 \mathrm{mg} / \mathrm{kg})>\mathrm{Cd}$ $(14.77 \mathrm{mg} / \mathrm{kg})$. The mean concentration of these metals exceeded the reference values. The areal distribution of the reported heavy metals showed specific and non-specific patterns indicating point and non-point pollution sources. The heavy metals potential sources in house dust in the study area were characterized using correlation, Principle components and cluster analyses. The potential sources for $\mathrm{Cd}, \mathrm{Cu}$ and $\mathrm{Pb}$ were interior and exterior sources, while the $\mathrm{Ni}$ and $\mathrm{Cr}$ were derived from internal sources. This study provides the environmental protection managers and decision-makers with important information about heavy metals concentrations and their sources in indoor environments.
\end{abstract}

Keywords: Metals; Pollution; Indoor dust; Iraq

\section{Introduction}

Globally, indoor environments have attracted increasing interest due to the rapid urbanization (Shi and Wang, 2021). People spend the majority of their time in indoor environments (homes, workplaces, schools ... etc.) exposed to the air of those environments (Andrade and Dominski, 2018). The chances of exposure to indoor environment pollutants increase by 1,000 times compared to the chances of exposure to those pollutants in outdoor environments (Hwang et al., 2008). Among the pollutants of dangerous indoor environments are heavy metals that have received great attention among people due to their high toxicity, non-degradable and harmful effects on humans. House dust acts as a sink and source of the heavy metals (Yadav et al., 2019; Arar et al., 2019). Household dust is defined as the fine settled or particulate airborne materials found in the indoor household environment. Household dust is defined as a mixture of organic and inorganic particles generated from atmospheric precipitation, anthropogenic activities, and outdoor dust transport (Hassan, 2012). Regardless of the source of the

DOI: 10.46717/igj.54.2F.11ms-2021-12-28 
heavy metals, whether natural or human, heavy metals tend to settle and accumulate in internal floor dust (Arar et al., 2019, Clark et al., 2020). The heavy metals sources in household dust are classified into endogenic and exogenicl sources. The endogeneic sources comprise materials used by residents of the house (such as, cookers, heaters, consumer products, building materials, and furniture) as well as daily activities (such as smoking, burning incense, vacuuming, cleaning and leakage of external pollutants (Kabata-Penias, 2011; Awadh, 2015). The exogenic sources include traffic emissions, road dust, as some heavy elements are liberated from tire wear, and metal parts corrosion of vehicles (Lavado et al., 2007). In recent years, House dust contaminated with heavy metals has received more and more attention as it relates to health of human. A numerous studies have been performed to evaluate the metals concentrations in household dust around the world, e.g., India (Kumar and Scott, 2009; Yaparla et al., 2019 ), Australia (Chattopadhyay et al., 2003), Turkey (Kurt-Karakus, 2012 ), China (Zhao et al., 2020, Cheng et al., 2018; Wang et al., 2020), Saudi Arabia (Albar et al., 2019), Iran (Sobhanardakani, 2018; Hashemi et al., 2020), Canada (Al Hejami et al., 2019), Jordan (Arar et al., 2019; Al-Madanat et al., 2017), Egypt (Jadoon et al., 2020), Nepal (Yadav et al., 2019), Trinidad, WI (Clark et al., 2020), USA (Matt et al.,2021). A study was conducted on indoor dust pollution (classroom dust) in primary schools and kindergartens in Ramadi City, Iraq (Rahdi et al., 2021). As far as we know so far, no study has been carried out on household dust contamination with metals in Iraq. Thus, this research is the first attempt to evaluate the HMs levels in the household dust in Iraq. The objectives of this work are to (1) measure of some metal's concentrations in house dust in Al-Fallujah City, Iraq, (2) investigate the spatial distribution of metals in the house dust, and (3) identify the metals sources in the house dust.

\section{Materials and Methods}

\subsection{Study Area Description}

Fallujah City is located to the west of the capital of Iraq, Baghdad, at latitude $33^{\circ} 21^{\prime} 13^{\prime \prime} \mathrm{N}$ and Longitude $43^{\circ} 46^{\prime} 46^{\prime \prime}$ E, Figure 1. The population of Al-Fallujah City is 426770 inhabitants in 2020 and the area of Al-Fallujah City Centre is $478 \mathrm{Km}^{2}$ (CSO, 2020). The climate of Fallujah City is hot desert with little precipitation in winter. Fallujah City is distinguished by its traffic density and various industrial activities.

\subsection{Sampling Collection and Analysis}

From October to November 2020, the dust samples were collected from fifty households randomly distributed (Fig. 2). The dust was sampled from every part (door sills, windows sills, and floors) in the household except for kitchens and bathrooms. The dust was collected using brushes and aluminum paper and reserved in zipper bags. The samples were dried at $104 \mathrm{oC}$ for two days and then sieved by using a stainless-steel sieve of $106 \mu \mathrm{m}$ diameter. The dust samples were then homogenized with porcelain pestle and mortar. They were held in a polyethylene vessel arranged for assimilation and examination. Closed container microwave-assisted acid assimilation method beneath large temperature and pressure has been rut (CCME, 1999), which evades the exogenic pollution and entails shorter period of time and littler amounts of acids, thus promoting limits of detection and total accuracy of the testing technique (Valeria et al., 2003). Half grams of dust sample were put into the reference vessel. Twenty-five milliliters of mixture (HCl: H2SO4: HNO3, 3:2:1) was then added to the reaction container which was introduced into the unit of microwave. After digestion, solution is cooled and filtrated. The filtrated sample was then pretended to $50 \mathrm{ml}$ with filtered water and kept in specific vessels. AAS (Atomic Absorption Spectrometry) instrument (Phoenix - 986, USA) was used to measure heavy metal level in the dust samples. 


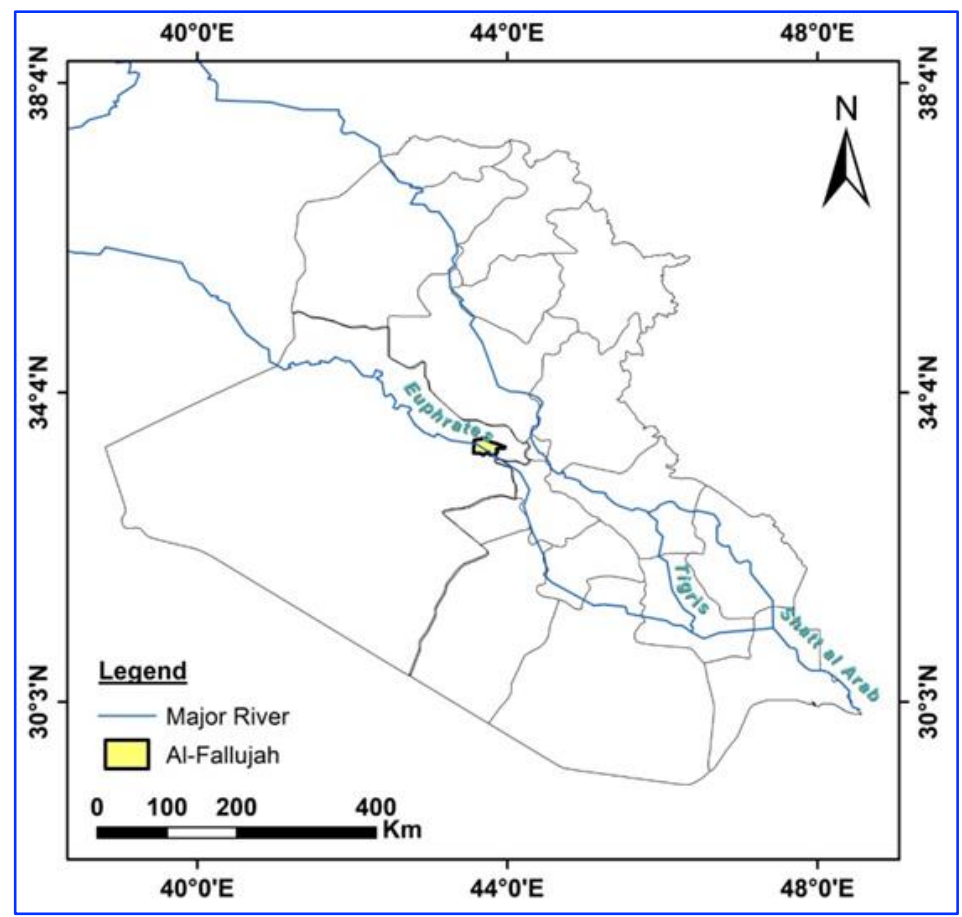

Fig. 1. Location map of Al- Fallujah City

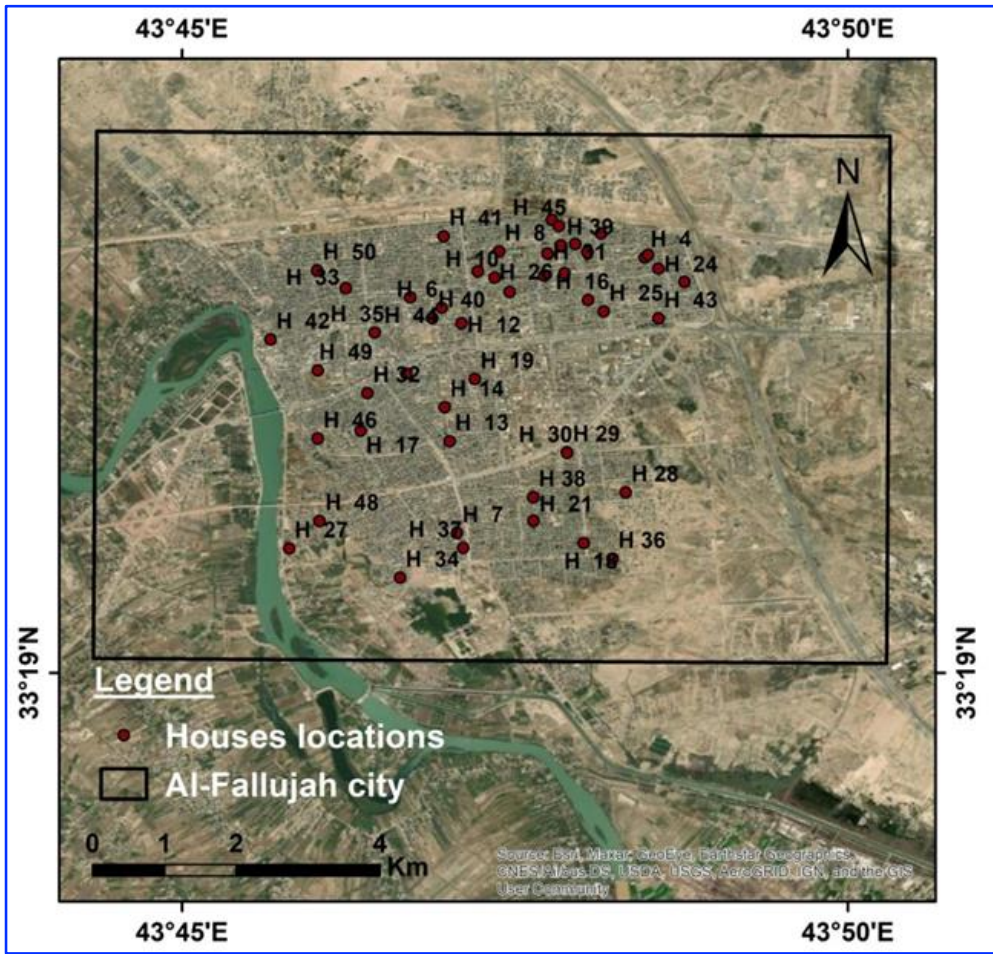

Fig. 2. Locations of the sampled households in Al- Fallujah City

\subsection{Identification of Potential Sources of Heavy Metals}

Three statistical methods, correlation matrix, cluster analysis (CA) and principal component analysis (PCA) were employed to identify heavy metals sources in soils (Yaylah-Abanuz, 2011), in 
sediment (Arfaeinia et al., 2019) and indoor dust (Hashemi et al., 2020; Rahdi et al., 2021). The results of used methods partly confirm each other (Zgłobicki et al., 2018).

\subsubsection{Correlation Matrix Analysis}

The matrix correlation analysis is a statistical method used for potential linear evaluation. The accurate use of correlation depends on the type of parameter and on the types of existing variables studied (Mukaka, 2012). It is also known as effective factor analysis to exhibit the relations between multiplied variables, including affecting factors, beside the chemical elements sources (Li et al., 2013). The coefficient of correlation $(\mathrm{Cf}>0.7)$ is interpreted as a strong correlation, while the value between $(\mathrm{Cf}=0.5-0.7))$ reflects a moderate correlation and the value of the correlation coefficient $(\mathrm{Cf}<0.5)$ is interpreted as a low correlation (Pam et al., 2011).

\subsubsection{Cluster Analysis (CA)}

CA is a preparatory method for data analysis for the purpose of resolving the data sorting problem. This method aims to sort data into nodules or groups. Each cluster exhibits high internal homogeneity and high external heterogeneity (McGarigal et al., 2013). The most common method in cluster analysis is Hierarchical Cluster Analysis, which begins by sorting the data into separate clusters and then links the clusters together stepwise until only one cluster exists (McKenna, 2003). The cluster analysis results are represented in form of Dendogram or Binary tree (Soffianian et al., 2014).

\subsubsection{Principle Components Analysis (PCA)}

PCA is a method of analyzing observations expressed in matrix data form described by several Dependent Variables that are generally inter-correlated (Adeyi and Torto, 2014). The analysis of the basic components aims to obtain important information in the form of a set of previously inferred variables which are called the basic components, factors, eigenvectors, and loadings. Each unit is assigned a score that correlates with its prediction on PCs.

\subsection{Quality Assurance and Quality Control (QA/QC)}

Quality Assurance and Quality Control (QA/QC) include the procedural blank, duplicate analysis and standard reference materials (BDH from UAE). Recovery ratios for the metals in the standard reference material were $99.92 \%(\mathrm{Cd}), 99.22 \%(\mathrm{Co}), 96.43 \%(\mathrm{Cr}), 99.43 \%(\mathrm{Cu}), 98.65 \%(\mathrm{Ni}), 97.32 \%$ $(\mathrm{Pb})$ and $98.72 \%(\mathrm{Zn})$, respectively.

\subsection{Statistical Analysis}

The descriptive statistics, correlation matrix analysis, principal component analysis (PCA), and cluster analysis (CA) were performed using the academic statistics software package STATISTICA version 13.3 for Windows.

\section{Results and Discussion}

\subsection{Heavy Metals in Household Dust}

Results of the descriptive statistics of heavy metals concentrations in household dust in Al-Fallujah City are listed in Table 1 . The descending order of heavy metals concentrations in household dust in Al-Fallujah City is as follows: $\mathrm{Zn}(292.85 \mathrm{mg} / \mathrm{kg})>\mathrm{Cr}(298.45 \mathrm{mg} / \mathrm{kg})>\mathrm{Ni}(105.72 \mathrm{mg} / \mathrm{kg})>\mathrm{Pb}(75.57$ $\mathrm{mg} / \mathrm{kg})>\mathrm{Cu}(65.03 \mathrm{mg} / \mathrm{kg})>\mathrm{Cd}(14.77 \mathrm{mg} / \mathrm{kg})$. The coefficient of variance $(\mathrm{CV})$ is used to explain the areal changeability of metals. In this study, the CV of metals in house dust ranged from 35.19 to $72.43 \%$. 
The heavy metals $(\mathrm{Cd}, \mathrm{Cr}, \mathrm{Cu}, \mathrm{Ni}, \mathrm{Pb}$, and $\mathrm{Zn})$ exhibited relatively higher changeability in household dust indicating the potential point source pollution. The $\mathrm{Cr}$ had the largest $\mathrm{CV}$ with a value of $72.43 \%$, reflecting higher variation of $\mathrm{Cr}$ in household dust, while the $\mathrm{Ni}$ had the lowest $\mathrm{CV}$ with a value of $35.19 \%$, pointing to weak variability and stable distribution within the area of study.

Table 1. Descriptive statistics of total concentration $(\mathrm{mg} / \mathrm{kg}$ ) of heavy metals in household dust in AlFallujah City, with values of international guidelines

\begin{tabular}{cccccccc}
\hline \multirow{2}{*}{ Metal } & Mean & Min. & Max. & Std. Dev. & Coef. Var. & \multicolumn{2}{c}{ Guidelines } \\
\cline { 6 - 8 } & & & & & CVEPA & CCME \\
$\mathrm{Cd}$ & 14.77 & 4.15 & 29.95 & 6.77 & 45.83 & SQG & SQG \\
$\mathrm{Cr}$ & 289.45 & 32.00 & 650.25 & 209.67 & 72.43 & 0.6 & 10 \\
$\mathrm{Cu}$ & 65.03 & 16.00 & 264.10 & 45.66 & 70.22 & 16 & 64 \\
$\mathrm{Ni}$ & 105.72 & 48.35 & 195.15 & 37.20 & 35.19 & 16 & 63 \\
$\mathrm{~Pb}$ & 75.57 & 35.65 & 168.60 & 28.83 & 38.15 & 40 & 140 \\
$\mathrm{Zn}$ & 292.85 & 40.25 & 586.50 & 145.59 & 49.71 & 110 & 200 \\
\hline
\end{tabular}

The heavy metals concentration in dust was compared with soil guidelines for metals because there are no dust guidelines for heavy metals. The United States Soil Quality Guidelines (USSQG) and the Canadian Soil Quality Guidelines (CSQG) provided by the United States Environmental Protection (USEPA, 1999) and Canadian Council of Ministers of the Environment (CCME, 2014), respectively, were used for comparison purpose in the present study. The mean concentrations of $\mathrm{Cd}, \mathrm{Cr}, \mathrm{Cu}, \mathrm{Ni}, \mathrm{Pb}$, and $\mathrm{Zn}$ exceeded the acceptable levels in the USSQG, while all the metals are higher than the references values in the CSQG except for $\mathrm{Pb}$ was lower than the acceptance level. Due to the lack of published studies on the of heavy metals concentrations in Iraqi cities, the mean concentration of metals in house dust in Al-Fallujah City have been compared with the mean concentration of the same metals in cities across the world, Table 2. The $\mathrm{Cu}, \mathrm{Pb}$, and $\mathrm{Zn}$ concentrations in household dust from Al-Fallujah City were less than in the cities from Australia, China, Iran, Saudi Arabia, while the $\mathrm{Cd}, \mathrm{Cr}$, and $\mathrm{Ni}$ concentrations were higher than in house dust from all cities. The comparison result is likely a result of different endogenic sources of metals present in indoor particles and different exogenic sources of metals inserted to the houses.

Table 2. The concentrations of heavy metals in household dust from Al-Fallujah City, Iraq and other cities.

\begin{tabular}{|c|c|c|c|c|c|c|c|c|}
\hline \multirow{2}{*}{ Country } & \multirow{2}{*}{$\begin{array}{c}\text { No of } \\
\text { samples }\end{array}$} & \multicolumn{6}{|c|}{ Concentration mean (mg/kg) } & \multirow{2}{*}{ Reference } \\
\hline & & Cd & $\mathrm{Cr}$ & $\mathbf{C u}$ & $\mathbf{N i}$ & $\mathbf{P b}$ & Zn & \\
\hline Al-Fallujah, Iraq & 50 & 14.77 & 289.45 & 65.03 & 105.7 & 75.57 & 292.85 & This study \\
\hline Sydney, Australia & 82 & 1.64 & 64.5 & 93.3 & 15.1 & 76.2 & 372 & Chattopadhyay et al. (2003) \\
\hline Chengdu, China & 90 & 2.37 & 82.7 & 161 & 52.6 & 123 & 657 & Cheng et al. (2018) \\
\hline Bushehr, Iran & 19 & 5.31 & 143.20 & 186.09 & 57.09 & 209.0 & 567.18 & Hashemi et al.2020 \\
\hline Toronto, Canda & 67 & 1.7 & 42 & 136 & 23 & 36 & 386 & Al Hejami et al.(2019) \\
\hline Jeddah, Saudi Arabia & 20 & 0.54 & 46.7 & 94.1 & 32.2 & n.a & 489 & Albar et al. (2019 \\
\hline Alexandria, Egypt & 24 & 0.77 & 29.2 & 141 & 25.1 & 260 & 771 & Jadoon et al. (2020) \\
\hline Istanbul, Turkey & 31 & 0.80 & 54.9 & 156 & 263 & 28.1 & 832 & Kurt-Karakus (2012) \\
\hline
\end{tabular}

\subsection{Spatial Distribution of Heavy Metals}

Maps of the spatial distribution of heavy metals were constructed using Arc map (version 10.8) software, (Fig. 3). The distribution map of Cd concentrations shows a number of hot spots (high anomalies) distributed over on the entire of the study area that may be attributed to the common effect of point-pollution endogenic sources and non-point pollution exogenetic sources of $\mathrm{Cd}$. The spatial distribution map of $\mathrm{Cr}$ concentration showed a remarkable change in the distribution, as there are many hot spots (high concentration) in the sample collection sites located in the old city as well as in the south 
eastern parts of the study area adjacent to the industrial city. This distribution reflects the common contribution of both indoor and outdoor $\mathrm{Cr}$ sources. In general, there is a similarity in the spatial distribution pattern between chromium and cadmium, and this may indicate the common source of both. The spatial distribution map did not show a specific type of distribution as was evident in the spatial distribution of cadmium and chromium. There is limited number of hot spots in the $\mathrm{Cu}$ spatial distribution map and this may explain in the term of the external source of copper or the non-point source of pollution.

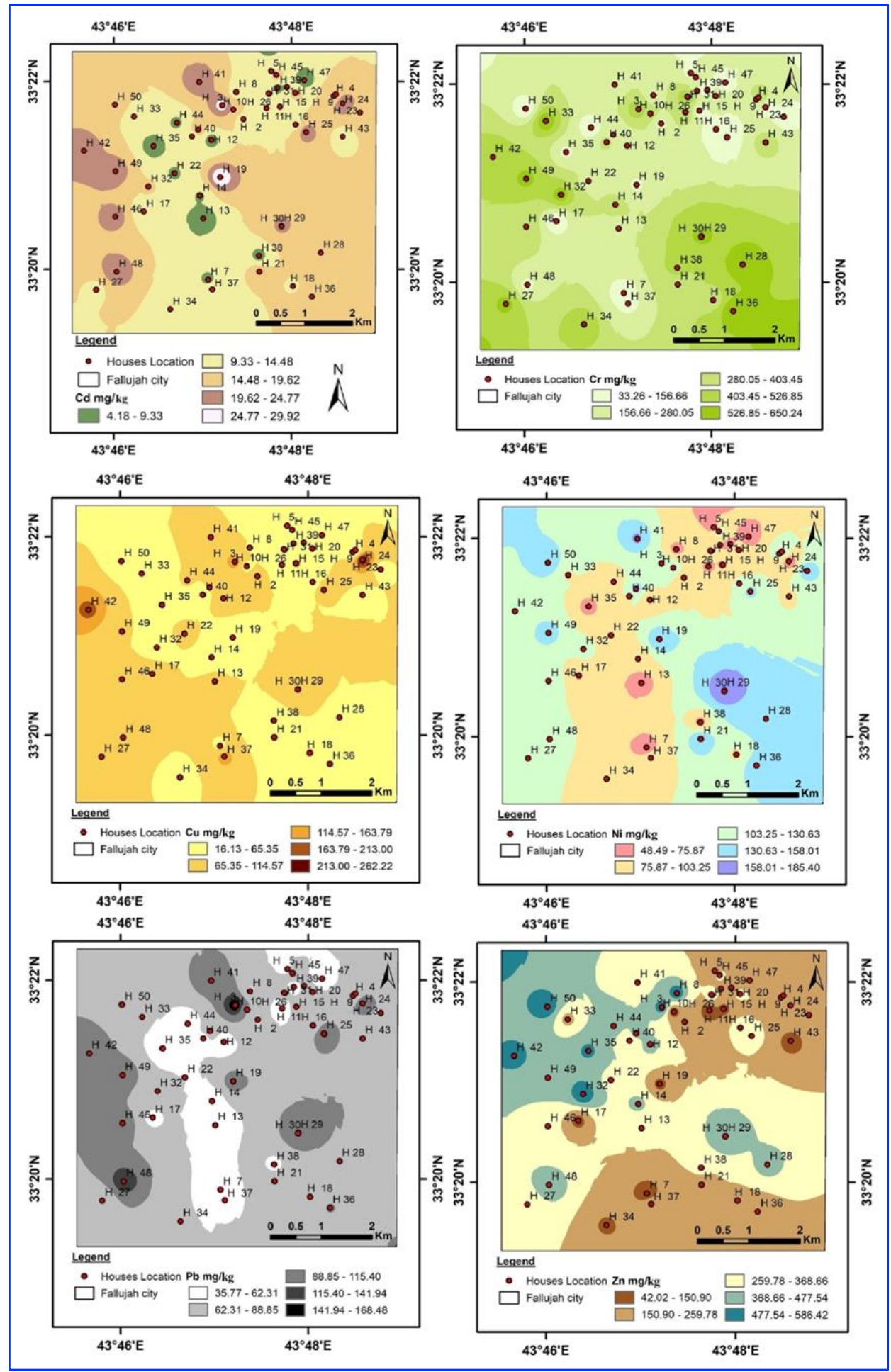

Fig.3. Spatial distribution maps of heavy metals in household dust in Al-Fallujah City. 
The spatial distribution of Ni concentrations in household dust in Fallujah city showed an increase in the concentration in the sample collection sites in the south eastern parts close to the industrial region, and an only one hot spot (high anomaly) appeared in these parts. The small number of hot spots is explained in the term of non-point sources of $\mathrm{Ni}$. There are two hot spots (high anomalies) $\mathrm{P} \mathrm{Pb}$ concentrations in house dust in Al-Fallujah, one of them located in the south western part and the other in the north central part. The distribution map did not show a specific distribution pattern, and this may reflect the diversity of lead dust pollution sources. The spatial distribution map of $\mathrm{Zn}$ concentrations showed a distribution pattern different from the rest of the heavy elements in the studied area. The hot spots were distributed in the northwest and north central parts of the studied area. The pattern of distribution of concentrations can be explained in terms of point sources and / or non-point sources of pollution.

\subsection{Identification of Potential Sources of Heavy Metals}

\subsubsection{Correlation matrix analysis}

The correlation matrix analysis results were used to investigate the interrelationships among metals in household dust in Al-Fallujah City and their potential origins or sources. The significant positive good and strong correlation relations indicate the common origin / source and routes of the heavy metals. The correlation coefficients for metals in the household dust of Al-Fallujah City are listed in Table 3. A significant positive correlation at $\mathrm{P}<0.05$ was found between $\mathrm{Cd}-\mathrm{Cu}(\mathrm{R}=0.32), \mathrm{Cd}-\mathrm{Ni}(\mathrm{R}=0.73)$, and $\mathrm{Cd}-\mathrm{Pb}(\mathrm{R}=0.92)$. The correlation analysis showed significant positive correlation relations between $\mathrm{Cr}-$ $\mathrm{Ni}(\mathrm{R}=0.45), \mathrm{Cr}-\mathrm{Pb}(\mathrm{R}=0.29), \mathrm{Cu}-\mathrm{Pb}(\mathrm{R}=0.37)$, and $\mathrm{Ni}-\mathrm{Pb}(\mathrm{R}=0.65)$. These positive significant correlation relations can be interpreted in term of the common sources/origins.

Table 3. Pearson correlation coefficient of heavy metals in households' dust in Al-Fallujah City, marked correlations are significant at $\mathrm{P}<0.05$.

\begin{tabular}{lllllll}
\hline Metal & $\mathbf{C d}$ & $\mathbf{C r}$ & $\mathbf{C u}$ & $\mathbf{N i}$ & $\mathbf{P b}$ & $\mathbf{Z n}$ \\
\hline $\mathrm{Cd}$ & 1.00 & & & & & \\
$\mathrm{Cr}$ & 0.22 & 1.00 & & & & \\
$\mathrm{Cu}$ & $\mathbf{0 . 3 2}$ & -0.11 & 1.00 & & & \\
$\mathrm{Ni}$ & $\mathbf{0 . 7 3}$ & $\mathbf{0 . 4 5}$ & -0.08 & 1.00 & & \\
$\mathrm{~Pb}$ & $\mathbf{0 . 9 2}$ & $\mathbf{0 . 2 9}$ & $\mathbf{0 . 3 7}$ & $\mathbf{0 . 6 5}$ & 1.00 & \\
$\mathrm{Zn}$ & 0.20 & 0.17 & 0.25 & 0.18 & 0.27 & 1.00 \\
\hline
\end{tabular}

\subsubsection{Principle component analysis (PCA)}

PCA was employed to detemine the heavy metals sources in household dust in Al-Fallujah City by applying varimax rotation with Kaiser Normalization. The results of PCA are listed in Table 4. Two large factors were extracted with an eigenvalue greater than 1 and constituted $69.93 \%$ of total variance. Factor 1 elucidated $48.23 \%$ of variation in metal data with largest positive loadings on $\mathrm{Ni}(0.89), \mathrm{Cr}$ (0.72), $\mathrm{Cd}(0.65)$, and $\mathrm{Pb}(0.63)$. Cr leaching, which preserves wood used in household furniture, is a source of chrome in household dust (4). $\mathrm{Cr}, \mathrm{Cd}$ and $\mathrm{Ni}$ in household dust are derived from stainless steel and the efflorescence of alloy (Cheng et al., 2018). The indoor smoking cigarettes of tobacco could release the $\mathrm{Pb}, \mathrm{Cd}$ and $\mathrm{Ni}$ into the house dust (Matt et al., 2021; Pourkhabbaz and Pourkhabbaz, 2012). $\mathrm{Pb}$ and $\mathrm{Cd}$ released from color pigments and ornamental material could directly contaminate the household dust (Jabeen et al., 2001; Yoshinaga et al., 2014; Hashemi et al., 2020). Factor 1 is indicated to indoor anthropogenic sources for $\mathrm{Cd}, \mathrm{Cr}, \mathrm{Ni}$, and $\mathrm{Pb}$. The significant correlations among $\mathrm{Cd}, \mathrm{Cr}, \mathrm{Ni}$ 
and $\mathrm{Pb}$ refer to similar sources particularly from the anthropogenic sources which support the PCA results. Factor 2 explained 21.70 the total variance and positive great loadings on $\mathrm{Cu}(0.85), \mathrm{Pb}(0.69)$ and $\mathrm{Cd}(0.66)$. The vehicle, traffic emissions and emissions from lubricating oil combustion, vehicle oils, tire wear, engine wear and tear were accounted as $\mathrm{Cu}, \mathrm{Pb}$ and $\mathrm{Cd}$ sources in the external and internal dust (Al-Khashman 2004, 2007; Dwivedi et al.,2006 ; Men et al., 2018; Zgłobicki et al., 2018; Jin et al., 2019). Factor 2 is referred to outdoor human sources for $\mathrm{Cu}, \mathrm{Pb}$, and $\mathrm{Cd}$. The significant correlations among $\mathrm{Cu}, \mathrm{Pb}$, and $\mathrm{Cd}$ refer to common sources especially from the anthropogenic sources which support the PCA results. Factor 2 includes the $\mathrm{Zn}$ with low loading. The high concentration of $\mathrm{Zn}$ in dust comes from the smelting and mining industries (Du et al., 2014) and the wear of the moving car parts (tyer wear, brake, valves), (Al-Khashman, 2004).

Table 4. Factor loadings (varimax rotation) of heavy metals total concentrations in household dust in Al-Fallujah City, marked loadings are $>0.60$.

\begin{tabular}{ccc}
\hline Metal & Factor 1 & Factor 2 \\
\hline $\mathbf{C d}$ & $\mathbf{0 . 6 5}$ & $\mathbf{0 . 6 6}$ \\
$\mathbf{C r}$ & $\mathbf{0 . 7 2}$ & -0.13 \\
$\mathbf{C u}$ & -0.27 & $\mathbf{0 . 8 5}$ \\
$\mathbf{N i}$ & $\mathbf{0 . 8 9}$ & 0.20 \\
$\mathbf{P b}$ & $\mathbf{0 . 6 3}$ & $\mathbf{0 . 6 9}$ \\
$\mathbf{Z n}$ & 0.12 & 0.48 \\
Eigenvalue & 2.89 & 1.30 \\
\% Total & 48.23 & 21.70 \\
variance & & 69.93 \\
\hline \begin{tabular}{c} 
\% \\
\hline
\end{tabular}
\end{tabular}

\subsubsection{Cluster analysis $(C A)$}

The hierarchical cluster analysis (HCA) result for metals in house dust is illustrated in Fig. 4 as a dendrogram. Fig. 4 shows two clusters: (I) includes $\mathrm{Zn}$ and the cluster (II) contains $\mathrm{Cd}-\mathrm{Cu}-\mathrm{Cr}-\mathrm{Ni}-$ $\mathrm{Pb}$. The elements of (II) joint together at high degree of similarity, possibly suggesting a common origin or source and shows high degree of heterogeneity with cluster (I), may be originated from other origin or sources. The results of CA supported the results of PCA and correlation matrix analysis.

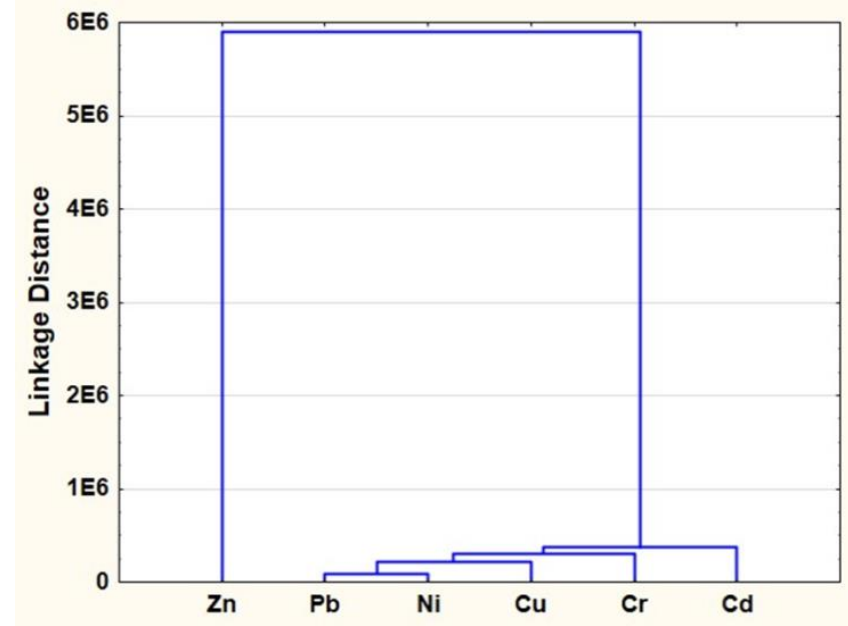

Fig.4. Dendrogram results of hierarchical cluster analysis for heavy metals in house hold dust in AlFallujah City 
Results of the correlation matrix analysis, $\mathrm{CA}$, and PCA showed that the $\mathrm{Cd}, \mathrm{Cu}$ and $\mathrm{Pb}$ in household dust in Al-Fallugah City may be derived from indoor and outdoor human sources, while the $\mathrm{Ni}$ and $\mathrm{Cr}$ released from indoor human sources. The $\mathrm{Zn}$ sources are coming from the industrial activities and the moving car parts.

\section{Conclusions}

The mean concentration of $\mathrm{Cd}, \mathrm{Cr}, \mathrm{Cu}, \mathrm{Ni}, \mathrm{Pb}$, and $\mathrm{Zn}$ in household dust in Al-Fallujah City is higher than the background guidelines suggesting pollution of house dust with heavy metals. The spatial distribution of the heavy metals in house dust showed specific patterns for some metals and non-specific for others indicating point-source and non-point pollution sources. The potential sources of heavy metals are interior /or exterior anthropogenic sources.

\section{Aknowledgements}

The authors express their gratitude to Dr. Khalid Farouk Al-Rawi, Department of Chemistry, College of Science, University of Anbar for his generous help in samples preparation and analysis. The authors are very grateful to the Editor in Chief Prof. Dr. Salih M. Awadh, the Secretary of Journal Mr. Samir R. Hijab. and the Technical Editors for their great efforts and valuable comments.

\section{References}

Adeyi, A.A. and Torto, N. 2014. Profiling heavy metal distribution and contamination in soil of old power generation station in Lagos, Nigeria. American Journal of Science and Technology, 1(1),1-10.

Al Hejami, A., Davis, M., Prete,D., Lu, J. and Wang, S. 2019. Heavy metals in indoor settled dusts in Toronto, Canada. Sci. Total Environment, 134895.

Albar, H. M. S. A., Ali, N., Eqani, S. A. M. A. S., Alhakamy, N. A., Nazar, E., Rashid, M. I., ... \& Ismail, I. M. I. (2020). Trace metals in different socioeconomic indoor residential settings, implications for human health via dust exposure. Ecotoxicology and environmental safety, 189, 109927.

Al-Khashman O.A., 2004. Heavy metal distribution in dust, street dust and soils from the work place in Karak Industrial Estate, Jordan. Atmospheric Environment, 38:6803-6812.

Al-Khashman O.A., 2007. Determination of metal accumulation in deposited street dusts in Amman, Jordan. Environment Geochemical Health, 29,1-10.

Al-Madanat, O., Jiries, A., Batarseh, M. and Al-Nasir,F. 2017. Indoor and outdoor pollution with heavy metals in Al-Karak City, Jordan. Journal International Environmental Application \& Science, 12,131-139.

Andrade, A. and Dominski, F.H. 2018. Indoor air quality of environments used for physical exercises and sports practice: systematic review. Journal Environment Management, 206, 577-586.

Arar, S., Al-Hunaiti, A., Masad, M., Maragkidou, A., Wraith, D. and Hussein, T. 2019. Elemental contamination in indoor floor dust and Its correlation with PAHs, Fungi, and Gram+/- Bacteria. International Journal Environment, 16, 3552.

Arfaeinia, H., Dobaradaran, S., Moradi, M., Pasalari, H., Mehrizi, E. A., Taghizadeh, F., Esmaili, A., and Ansarizadeh, M. 2019. The effect of land use configurations on concentration, spatial distribution, and ecological risk of heavy metals in coastal sediments of northern part along the Persian Gulf. Science of the Total Environment, 653, 783-791.

Awadh, S.M., 2015. Cd, Ni, and $\mathrm{Pb}$ distribution and pollution assessment in roadside dust from Baghdad City and Western Iraqi Desert. Arabian Journal of Geosciences, 8(1),.315-323.

Canadian Counsel of Ministers of Environment (CCME) .1999. Canadian water quality guidelines for protection of aquatic life. Canadian Water Quality Index 1.0. Technical Report, Canadian Environmental Quality Guidelines.

Canadian Counsel of Ministers of Environment (CCME). 2014. Canadian Soil Quality Guideline (residential/ parkland).

Central Statistical Organization (CSO). www.cosit.gov.iq. 
Chattopadhyay, G., Lin, K. and Feitz, A. 2003. Household dust metal levels in the Sydney metropolitan area. Environmental Research, 93(3), 301-307.

Cheng, Z., Chen, L., Li, H., Lin, J., Yang, Z., Yang, Y., Xu, X., Xian, J., Shao, J. and Zhu, X. 2018. Characteristics and health risk assessment of heavy metals exposure via household dust from urban area in Chengdu, China. Science of the Total Environment 619-620, 621-629.

Clark, C., Mohammed, F., Hamid, A. and Bent, G. 2020. Quantification and health risk assessment of heavy metals in residual floor dust at an indoor fringe range: A case study in Trinidad, WI. International Journal of Environmental Health Research,1793917.

Du P, Xie Y, F., Wang S. J., Zhao, H., Zhang, Z., Wu, B., Li, F., 2014. Potential sources of and ecological risks from heavy metals in agricultural soils, Daye City, China. Environment Science Pollution, 22, 34983507.

Dwivedi, D. Agarwal, A. and Sharma M. 2006. Particulate emission characterization of a biodiesel vs dieselfuelled compression ignition transport engine: A comparative study. Atmospheric Environment, 40, 5586-5595.

Hashemi, S. E., Fazlzadeh, M., Ahmadi, E., Parand, M., Ramavandi, B., Taghizadeh, F., \& Arfaeinia, H., 2020. Occurrence, potential sources, in vitro bioaccessibility and health risk assessment of heavy metal in indoor dust from different microenvironment of Bushehr, Iran. Environmental Geochemistry and Health, 42, 3641-3658.

Hassan, S. 2012. Metal concentrations and distribution in the household, stairs and entryway dust of some Egyptian homes. Atmospheric Environment, 54, 207-2015.

Hwang, H.M., Park, E.K., Young, T.M. and Hammock, B.D. 2008. Occurrence of endocrine -disrupting chemicals in indoor dust. Sci. Total Environment, 404, 26-35.

Jabeen, N., Ahmed, S., Hassan, S., and Alam, N. 2001. Levels and sources of heavy metals in house dust. Journal of Radioanalytical and Nuclear Chemistry, 247(1), 145-149.

Jadoon, W. A., Abdel-Dayem, S. M. M. A., Saqib, Z., Takeda, K., Sakugawa, H., Hussain, M., ... \& Syed, J. H. 2021. Heavy metals in urban dusts from Alexandria and Kafr El-Sheikh, Egypt: implications for human health. Environmental Science and Pollution Research, 28(2), 2007-2018.

Jin, Y., O'Connor, D., Ok, Y., Tsang, D., Liu, A. and Hou, D. 2019. Assessment of sources of heavy metals in soil and dust at children's playgrounds in Beijing using GIS and multivariate statistical analysis. Environment International 124, 320-328.

Kabata-Penias, A. 2011. Trace Elements in Soils and Plants. Taylor and Francis Group, CRC Press, 4th ed.

Kumar, A., and Scott, C. 2009. Lead loadings in household dust in Delhi, India. Indoor Air, 19, 414-420.

Kurt-Karakus, P. 2012. Determination of heavy metals in indoor dust from Istanbul, Turkey: estimation of the health risk. Environment international, 50, 47-55.

Lavado, R., Rodríguez, M., Alvarez, R., Taboada, M. and Zubillaga M. 2007. Transfer of potentially toxic elements from biosolid-treated soils to maize and wheat crops. Agri. Ecosystem \& Environment, 118, 312- 318.

Li, X. Liu, L .and Wang, Y., 2013. Heavy metal contamination of urban soil in an old industrial city (Shenyang) in Northeast China. Geoderma,192, 50-58.

Matt, G., Quintana, P., Hoh, E., Dodder, N., Mahabee-Gittens, E., Padilla, S., Markman, L. and Watanabe, K. 2021. Tobacco smoke is a likely source of lead and cadmium in settled house dust. Journal of Trace Elements in Medicine and Biology, 63.

McGarigal, K. Cushman, S.A. and Stafford, S. 2013. Multivariate statistics for wildlife and ecology research. Springer Science \& Business Media.New York,Inc.

McKenna, J.E., 2003. An enhanced cluster analysis program with bootstrap significance testing for ecological community analysis. Environmental Modeling and Software,18(3), 205-220.

Men, C., Liu, R., Xu, F., Wang, Q., Guo, L. and Shen, Z. 2018. Pollution characteristics, risk assessment, and source apportionment of heavy metals in road dust in Beijing, China. Science of The Total Environment, 612,138-147.

Mukaka, M.M. 2012. Statistics Corner: A guide to appropriate use of Correlation coefficient in medical research. Malawi Medical Journal, 24(3), 69-71. 
Pam, E. Akiti, T. Osae, S., Ganyaglo, S., and Gibrilla, A. 2011. Multivariate cluster analysis of some major and trace elements distribution in an unsaturated zone profile, Densu River Basin, Ghana. African Journal of Environmental Science and Technology,5 (3),155-167.

Pourkhabbaz, A., \& Pourkhabbaz, H., 2012. Investigation of toxic metals in the tobacco of different Iranian cigarette brands and related health issues. Iranian Journal of Basic Medical Sciences, 15(1), 636.

Radhi, A., Shartooh, S. and Al-Heety, E. 2021. Heavy metals pollution and sources in dust of the primary schools and kindergartens in Ramadi City, Iraq. Iraqi Journal of Science (Accepted).

Shi, T., \& Wang, Y., 2021. Heavy metals in indoor dust: spatial distribution, influencing factors, and potential health risks. Science of The Total Environment, 755, 142367.

Sobhanardakani, S. (2018). Non-carcinogenic risk assessment of heavy metals through exposure to the household dust (Case study: City of Khorramabad, Iran). Annals of Military and Health Sciences Research, 16(4).

Soffianian, A. Madani, E. and Arabi, M. 2014.Risk Assessment of Heavy Metal Soil Pollution through Principal Components Analysis and False Color Composition in Hamadan Province, Iran. Environmental System Research, 3 (3), 2193-2697.

US Environmental Protection Agency (USEPA). 1999. Screening Level Ecological Risk Assessment Protocol for Hazardous Waste Combustion facilities, Appendix E: Toxicity Reference Values, Vol. 3.

Valeria, S., Smith, C. and Donovan, A. 2003. Microwave digestion for sediment, soil and urban particulate matter for trace metal analysis. Talanta, 60, 715-723.

Wang, Y., Fang, F., Lin, Y., Cai, J., Zhang, C., \& Ge, Y. (2020). Pollution and influencing factors of heavy metals from rural kitchen dust in Anhui Province, China. Atmospheric Pollution Research, 11(7), 1211-1216.

Yadav, I.C., Devi, N.L., Singh, V.K., Li, J. and Zhang, G. 2019. Spatial distribution, source analysis, and health risk assessment of heavy metals contamination in house dust and surface soil from four major cities of Nepal. Chemosphere 218, 1100-1113.

Yaparla, D., Nagendra, S. S., \& Gummadi, S. N., 2019. Characterization and health risk assessment of indoor dust in biomass and LPG-based households of rural Telangana, India. Journal of the Air \& Waste Management Association, 69(12), 1438-1451.

Yaylah-Abanuz, G. 2011. Heavy metal contamination of surface soil around Gebze Industrial Area, Turkey. Microchemistry Journal, 99(1), 82-92.

Yoshinaga, J., Yamasaki, K., Yonemura, A., Ishibashi, Y., Kaido, T., Mizuno, K., ... \& Tanaka, A., 2014. Lead and other elements in house dust of Japanese residences-Source of lead and health risks due to metal exposure. Environmental Pollution, 189, 223-228.

Zgłobicki, W., Telecka, M., Skupiński, S., Pasierbińska, A. and Kozieł, M. 2018. Assessment of heavy metal contamination levels of street dust in the city of Lublin, E Poland. Environmental Earth Sciences, 77,774.

Zhao, X., Li, Z., Tao, Y., Wang, D., Huang, J., Qiao, F., Lei, L. and Xing, Q. 2020. Distribution characteristics, source appointment, and health risk assessment of $\mathrm{Cd}$ exposure via household dust in six cities of China. Building and Environment, 106728. 